\title{
Thermal stability of soil organic matter of Typical Chernozems under different land uses
}

Volkov D.S. ${ }^{1,2}$, Rogova O.B. ${ }^{2}$, Proskurnin M.A. ${ }^{1}$, Farkhodov Yu.R. ${ }^{2}$

${ }^{1}$ Chemistry Department of M.V. Lomonosov Moscow State University, Moscow, Russia, 119991

${ }^{2}$ Department of Chemistry and Physical Chemistry of Soils, V.V. Dokuchaev Soil Science Institute, Moscow 119017, Russia

doi: 10.36291/HIT.2019.volkov.050

Chernozems are among the most fertile soils relevant for global food production and the main part of productive agricultural land in Russia is confined to Chernozems. Soil organic matter (SOM) of bulk samples and size fractions (by dry screening) of Chernozems with a rather wide agricultural use history (from intact steppe to permanent bare fallow) was studied by thermogravimetry (TGA) under pyrolysis conditions in an inert atmosphere to approach its transformation depending on the type of use. The data basis is a 55-year-long field experiment of the Kursk Research Institute of Agricultural Production and V.V. Alekhin Tsentralno-Chernozemny Nature Reserve of Russia. It was shown that the SOM of the formed deciduous tree shelterbelt soil is the least thermally stable over the whole decomposition temperature range and contains the maximum amount of thermally unstable compounds. Among the aggregates of this soil, the aggregates with a size of 1-2 $\mathrm{mm}$ are the most thermally stable, the least stable are $7-10 \mathrm{~mm}$ in size and less than 0.25 $\mathrm{mm}$, which is confirmed by the whole set of applied statistical criteria. Steppe soil stands out for its highest thermal stability formed over the centuries of lack of ploughing under predominant grassy vegetation. Moreover, all its aggregates contain predominant amounts of thermally unstable SOM, the most thermally stable are aggregates of $1-2 \mathrm{~mm}$. SOM recovery processes that occur in soil of the overgrown fallow and no-tillage farming if compared with the initial (bare fallow and cropland, respectively) are not the same. Predominant SOM accumulation occurs in aggregates of $0.5-1$ and $1-2 \mathrm{~mm}$.

With systematic observation of agricultural land, a statistically significant increase in T50 in the range of $170-600{ }^{\circ} \mathrm{C}$. A new parameter to assess the degree of organic matter degradation, the ratio of the mass loss in the $380-600$ to $170-380{ }^{\circ} \mathrm{C}$ temperature range that is referred to as two-range thermal stability ratio. It is shown that this relative index discriminates soil samples depending on the land use type and does not require the knowledge on carbon content. As well as a decrease in two-range thermal stability ratio, the same range may indicate the manifestation of SOM degradation processes and the need for measures to compensate for a decrease in thermally unstable SOM components. At the same time, state-of-the-art thermogravimetry is a highly automated method of analysis, which almost does not require consumables and operator time, and thus can be used in small laboratories.

Acknowledgements. This work was done as a part of the collaboration project with Skolkovo Institute of Science and Technology (Digital Agriculture Lab, CDISE). The authors acknowledge the financial support of The Ministry of Science and Higher Education of the Russian Federation, budget project 0591-2019-0024. 